\title{
A multinational review: Oesophageal cancer in low to middle-income countries (Review)
}

\author{
RODNEY HULL ${ }^{1}$, MZWANDILE MBELE ${ }^{1}$, TSHEPISO MAKHAFOLA ${ }^{1}$, CHINDO HICKS $^{2}$, SHAO MING WANG ${ }^{3}$, \\ RUI MANUEL REIS ${ }^{4}$, RAVI MEHROTRA ${ }^{5}$, ZILUNGILE MKHIZE-KWITSHANA ${ }^{6}$,

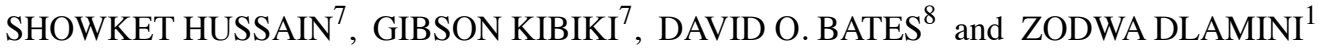

\begin{abstract}
${ }^{1}$ South African-Medical Research Council/University of Pretoria Precision, Prevention and Novel Drug Targets for HIV-Associated Cancers Extramural Unit, Cancer Research Institute, University of Pretoria, Faculty of Health Sciences,

Pretoria, Gauteng 0028, South Africa; ${ }^{2}$ Louisiana State University, School of Medicine, Department of Genetics, Bioinformatics and Genomics Centre, LA 70112, USA; ${ }^{3}$ National Cancer Centre, Cancer Hospital, Chinese Academy of Medical Sciences and Peking Union Medical College, Beijing 100730, P.R. China; ${ }^{4}$ Molecular Oncology Research Centre, Barretos Cancer Hospital, CEP 14784 400, Sao Paulo, Brazil; ${ }^{5}$ Indian Council of Medical Research, 110029 New Delhi, India; ${ }^{6}$ School of Medicine, University of Kwazulu-Natal, Durban, KwaZulu-Natal 4013, South Africa;

${ }^{7}$ East African Health Research Commission, East African Community, Quartier Kigobe, 1096 Arusha, United Republic of Tanzania; ${ }^{8}$ University of Nottingham, Queens Medical Centre, Cancer Biology, NG7 2UH Nottingham, UK
\end{abstract}

Received April 23, 2019; Accepted October 8, 2019

DOI: 10.3892/ol.2020.11902

\begin{abstract}
Oesophageal cancer (OC) is an aggressive neoplasm that manifests in the gastrointestinal tract and is the result of numerous factors that can contribute to the development of the disease. These may include old age, nutritional deficiencies, oesophageal obstruction and food ingestion difficulties. Environmental factors serve a large role in increasing the risk of developing OC. Two factors that serve an increasing risk of developing $\mathrm{OC}$ are the use of tobacco and the consumption of alcohol. Genetic factors also exhibit a large effect on the risk of developing OC, for example, the causative genes in Black Africans differ from other races. $\mathrm{OC}$ is 3-4 times more common among men than women. OC has been previously reported in $>450000$ individuals worldwide, and its incidence is increasing. The current review compares OC in low to middle-income
\end{abstract}

Correspondence to: Professor Zodwa Dlamini, South African-Medical Research Council/University of Pretoria Precision Prevention and Novel Drug Targets for HIV-Associated Cancers Extramural Unit, Cancer Research Institute, University of Pretoria, Faculty of Health Sciences, Bophelo Road, Prinshof 349-Jr, Room 4.35, Pathology Building, Pretoria, Gauteng 0028, South Africa

E-mail: zodwa.dlamini@up.ac.za

Abbreviations: AC, adenocarcinoma; ADHs, alcohol dehydrogenases; ALDH2, aldehyde dehydrogenase-2; ASR, age-standardised incidence rate; GWAS, genome wide association studies; OC, oesophageal cancer; ORCI, Ocean Road Cancer Institute; PGE2, prostaglandin $\mathrm{E}_{2}$; SCC, squamous cell carcinoma; SNPs, nucleotide polymorphisms

Key words: esophageal cancer, squamous cell carcinoma, adenocarcinoma, Barrett's esophagus, low to middle income countries, South Africa, Tanzania, China, India, Brazil countries with developed countries. The incidence of OC, particularly squamous cell carcinoma (SCC) is high in low and middle-income countries. In developed countries, the incidence of SCC is low compared with adenocarcinoma. The majority of OC cases are diagnosed in the late stages of the disease, leading to high mortality rates. The current review aimed to discuss factors that contribute to the development of this disease in different geographical areas and genetic mechanisms governing these findings. The current review also aims to discuss the preventative treatment options for the disease, and also discusses the diagnosis and surveillance in five LMICs, including South Africa, China, Tanzania, India and Brazil.

\section{Contents}

1. Introduction

2. Methods

3. Oesophageal cancer risk Factors

4. Epidemiology of oesophageal cancer

5. Oesophageal cancer in low to middle countries compared to developed countries

6. Molecular epidemiology of oesophageal cancer

7. Diagnosis and prognosis of oesophageal cancer

8. Oesophageal cancer treatment

9. Conclusions

\section{Introduction}

Oesophageal cancer (OC) is an aggressive neoplasm with its effect manifested in the gastrointestinal tract as a result of late diagnosis, old age and nutritional abnormalities which results from oesophageal obstruction and impossibility of proper food ingestion (1). 
The disease is more frequent in old age male individuals $(2,3)$. Oesophageal cancer is usually 3 to 4 times more common among men than women $(1,4)$. Oesophageal cancer is a disease that is reported in more than 450,000 individuals worldwide and its incidence is increasing. Squamous cell carcinoma (SCC) is the histological type that is predominant as compared to adenocarcinoma (AC) form. However, in well-developed countries a shift is observed where adenocarcinoma (AC) is predominant. This includes countries such as Australia, United Kingdom, United States of America and some Western European countries such as Finland, France and the Netherlands. The five-year survival of oesophageal patients ranges from 15 to $25 \%$ (5-7). Greater than 490,000 new cases of OC were reported in 2005 and the prevalence of oesophageal cancer (OC) is expected to increase by $14 \%$ while other types of cancers incidence are expected to decrease by $2025(8,9)$. Oesophageal cancer (OC) accounted for $>400000$ mortalities worldwide in 2000 (8), OC is considered as the eighth most common cancer and the sixth highest cause of cancer related mortalities worldwide with developing countries accounting $>80 \%$ of total cases and deaths $(8,10)$. Various risk factors are reported to be involved in the genesis of oesophageal tumours. The highest OC risk areas are found in Eastern Asia and Eastern and Southern Africa, Brazil, India and Kenya. The lowest OC risk areas are found in Western Africa (4). The aims of the current review are to compare oesophageal cancer in low to middle income countries, as an example, China, Brazil, India and South Africa to developed countries. According to the National Cancer Institute in the United States, approximately 17,990 new cases of OC cases were reported and 15,210 deaths occurred due to OC in 2013 (9). The five-year survival rate for all oesophageal cancers in the United States of America is 43\% in those individuals where the cancer has not spread. This drops to between 4 and $23 \%$ if the cancer spreads to different parts of the body.

The current review also focusses on the oesophageal cancer burden; risk factors, molecular epidemiology; genetic factors; diagnosis; prevention and treatment challenges of the disease in low and middle countries such as South Africa, China, India, Brazil and Tanzania compared to developed countries such as the United States.

In developing countries oesophageal cancer makes up approximately $80 \%$ of total cases and deaths $(11,12)$. Oesophageal cancer histological type and its incidence differs depending on geographic locations. The incidence is directly proportional to the related risk factors and economic development in variable countries. This variation in incidence is assumed to be based on usage or consumption of tobacco and alcohol as contributing risk factors (12). Table I $(4,13)$ shows the estimated new oesophageal cancer cases and deaths worldwide by sex. This data indicates that males are more affected than females in both well-developed and developing countries. The relative risk factors for developing oesophageal cancer depend on geographic locations as well as variations in histological types (Table II) $(11,13)$.

\section{Methods}

Literature searches were performed in PubMed using the following search terms; oesophageal cancer epidemiology; adenocarcinoma epidemiology; squamous cell carcinoma epidemiology; esophageal cancer incidence rate developed countries; esophageal cancer incidence rate low and muddle income countries, oesophageal cancer mortality developed countries, oesophageal cancer mortality low and muddle income countries, oesophageal cancer Biomarkers and oesophageal cancer treatment. In order to obtain country specific data the search term oesophageal cancer and the countries or geographical area name were used (USA, Europe, Asia, Africa's oesophageal cancer corridor, Brazil, China, India, South Africa and Tanzania). In addition to this the following search terms were used; oesophageal cancer geographic distribution, oesophageal cancer ethnicity, oesophageal cancer socioeconomic distribution, oesophageal cancer international trends. The name of the country was used in combination with the search term oesophageal cancer environmental risk factors, to obtain references for the risk factors for the population of these countries. Information on the genetic factors contributing to oesophageal cancer in each country was obtained by combining the country name and the following search terms; oesophageal cancer Genome-wide association study, oesophageal cancer non-coding mRNA and oesophageal cancer Genetic polymorphisms. Cancer statistics for oesophageal cancer were obtained from publications by the Surveillance, Epidemiology, and End Results (SEER) program and the World Health Organization) WHO). Data was also obtained from the GLOBOCAN database International Association of Cancer Registries (IACR). The ethnicity terms used are taken from the data sources that were searched and referenced.

\section{Oesophageal cancer risk factors}

The risk of developing oesophageal cancer increases with age with squamous cell carcinoma (SCC) occurring equally in the middle or lower oesophagus. The highest risk of oesophageal cancer has been indicated in individuals with ages that ranges between 45 and 70. According to Daly et al (2000) oesophageal cancer incidence is three times higher in black Africans as compared to their white counterparts (14) while Das et al (2015) indicated that the chance of black Africans developing $\mathrm{OC}$ is thought to be twice that for white individuals (5). There are major risk factors that have played an important role in these two subtypes of oesophageal cancer, depending on the area where the oesophageal cancer subtype occurred (14). As previously stated, two of the greatest risk factors are alcohol consumption and tobacco use (Fig. 1) $(15,16)$. Alcohol consumption is reported as the primary risk factor while alcohol consumption and tobacco use together have a synergistic effect and may increase the relative risk (9). Table II presents risk factors for oesophageal cancer and the histological type that each relative risk factor affects. One of the main reasons for males having a higher incidence of oesophageal cancer is that males have higher rates of alcohol and tobacco use (17). Smoking is an important risk factor for both $\mathrm{AC}$ and $\mathrm{SCC}$ while alcohol is a significant factor for SCC (18). Alcohol and tobacco use in combination leads to a substantial increase in the risk of oesophageal cancer. Users of both tobacco and alcohol have a relative risk of 35.4 in white males and 149.2 in African males as compared to the men of the same race and areas who neither smoke nor consume alcohol (19). The mechanism behind this increased risk by dual alcohol and tobacco use is because alcohol decreases or reduces metabolic activity within the cell, resulting in a reduction in the activity of detoxification enzymes, while 
A

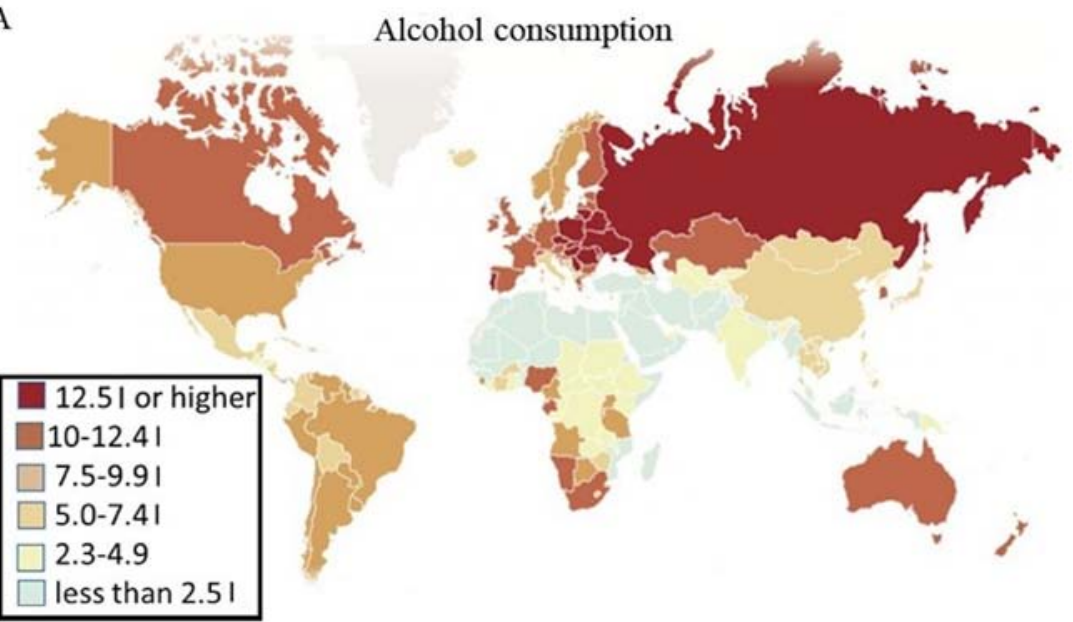

B

Tobacco consumption

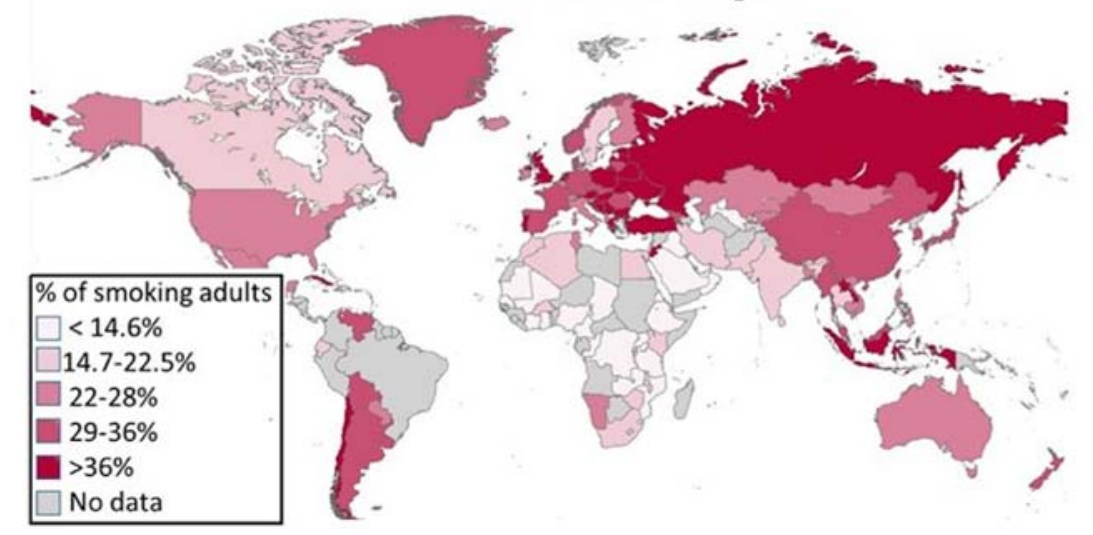

Figure 1. Alcohol and Tobacco consumption worldwide. (A) Alcohol consumption in liters of pure ethanol per person and (B) tobacco usage in percentage of adults smoking $(28,29)$.

Table I. Estimated new oesophageal cancer cases and deaths worldwide (Torre, 2016 \#264).

\begin{tabular}{lcc}
\hline Variable & $\begin{array}{c}\text { Estimated } \\
\text { new cases }\end{array}$ & Estimated deaths \\
\hline Worldwide & & \\
Male & 323,000 & 281,200 \\
Female & - & 119,000 \\
Developed countries & - & 56,100 \\
Male & - & - \\
Female & & 255,100 \\
Developing countries & 255,300 & 103,700 \\
Male & 114,400 & \\
Female & & \\
\hline
\end{tabular}

-, no data.

promoting oxidation. This results in increased damage to DNA and increased sensitivity to other environmental toxins (20). Tobacco carcinogens penetrate the oesophageal epithelium (21). Carcinogens in tobacco include aromatic amines, nitrosamines, polycyclic aromatic hydrocarbons, aldehydes and phenols $(21,22)$. Another risk factor for adenocarcinoma (AC) is obesity. This occurs in individuals with a predominately abdominal centered fat distribution. Hypertrophied adipocytes and inflammatory cells within fat deposits cause a low grade inflammation environment and promote tumour development through the release of adipokines and cytokines (23). In the tumour microenvironment, adipocytes supply energy production and support tumour growth and progression (24). Obesity is associated with an increased risk for adenocarcinoma (18), which may explain the increase in AC relative risk reportedly affecting individuals in developed countries like the United States and the United Kingdom, where alcohol and tobacco use is relatively lower than in developing countries. It has also been found that poor socio-economic status in low and middle developed countries results in a lower intake of fruits and vegetables. Fruits, vegetables and fish have been reported to play a major role in reducing the risk of development of oesophageal cancer (25). Regular, repeated consumption of hot beverages may cause chronic esophagitis and is strongly associated with a high risk of oesophageal cancer (26). Raw food contaminated by $\mathrm{N}$-necrosis-compounds are also suspected risk factors for the development of oesophageal cancer. Foods rich in these compounds include salted tea, which has a high 
Table II. Relative risk factors for oesophageal cancer (13).

\begin{tabular}{lcc}
\hline Risk factor & Squamous cell carcinoma & Adenocarcinoma \\
\hline First or second hand smoke & +++ & +++ \\
Alcohol consumption & + & - \\
Red meat consumption & - & - \\
Barrett's oesophagus & ++ & ++ \\
Reflux symptoms & ++++ & +++ \\
Overweight & ++++ & ++ \\
Poverty & +++ & - \\
Caustic injury to the oesophagus & + & - \\
History of head and neck cancer & +++ \\
Frequent consumption of hot drinks & +
\end{tabular}

-, no effect; +, suspicious effect; ++, positive effect; +++ and ++++, strong positive effect.

methylation activity, leading to the endogenous formation of nitrosamines (27-29).

\section{Epidemiology of oesophageal cancer}

Oesophageal cancer has two histological subtypes: Squamous cell carcinomas (SCC) and adenocarcinomas (AC). SCC develops mostly in flat cell linings whereas $\mathrm{AC}$ arises from cells located in the lower third of the oesophagus and originate predominantly from Barrett mucosa (30). SCC and Barrett's develop from high-grade dysplastic pre-cancerous tissue. AC develops from the progression of Barrett's oesophagus from metaplastic to dysplastic tissue and invasive carcinoma (31). SCC incidence rates are high in countries that fall into two geographical regions. One region is named the 'Asian oesophageal cancer belt' and stretches from northern China to the Middle East (32). Another area is known as the East Africa oesophageal cancer corridor and stretches from South Africa to Somalia. This indicates that oesophageal cancer incidence and its histological type differs depending on risks factors on those particular geographic areas $(9,18)$.

\section{Oesophageal cancer in low to middle countries compared to developed countries}

Low socioeconomic conditions are associated with higher incidence and mortality of oesophageal cancer in specific areas around the world, with the exception of China $(33,34)$. It is important to analyse changes in the incidence and mortality rate of oesophageal cancer in the context of territorial socioeconomic disparities, this is especially true in countries affected by inequalities in healthcare. Fig. 1 llustrates the higher prevalence of SCC in low and middle-income countries.

Countries in the oesophageal cancer corridor. The regions with the highest number of cases and most deaths are the south and the east of Africa, central Asia, Turkey, Iran, Kazakhstan and China (Fig. 2) (35,36). The Southern Africa region has the highest incidence of oesophageal cancer worldwide (4). Oesophageal cancer is a rare disease in Western Africa, with incidence rates of 0.8 and 0.4 in males and females respectively (4). This may be because they have not changed their life style, for example their diet, drastically in the last few decades. Fig. 1 illustrates the prevalence of AC in well-developed countries. India also falls within the Asian oesophageal-cancer belt and has a high incidence rate of oesophageal cancer (26).

South Africa. In South Africa oesophageal cancer is the eighth most common cancer in men and the eleventh in woman. In the early 20th century esophageal cancer was an uncommon disease in South Africa (37). From the 1940s, there was a rapid rise in the number of EC cases until esophageal cancer became the third most commonly diagnosed cancer in Black South Africans (38-40). In the African population group the ASR was 22.3 per 100,000 in males and 11.7 per 100,000 in females (41). In the African or mixed ancestry population group EC is the fourth highest cause of death in males (42). The area with the highest incidence is the Transkei region (43) with an ASR of 46.7/100,000 for males and 19.2/100,000 for females (44). When this disease is defined by sex and race, a slightly different picture emerges. A decrease in both SCC and $\mathrm{AC}$ becomes evident, especially when comparing African males and females with their non-African counterparts $(37,45)$. However, other studies have found that there has only been a decrease in the prevalence of AC in South Africa (8). The areas in South Africa with the highest incidence of OC include the former Transkei region. This area was then a homeland settlement, with limited healthcare resources.

The increased incidence of EC in South Africa over the last decades is largely due to changes in lifestyle, diet, and the exposure to carcinogens (43). EC rates are highest in the 60 to 70-year age group. The two most important risk factors include cigarette fuming and extreme alcohol use (46). Approximately $17.6 \%$, of adult South Africans use tobacco, $29.2 \%$ of males and $7.3 \%$ in females (47). South Africans consume $>53 \mathrm{~g}$ of ethanol per day, which leads to a 5 times greater risk of developing esophageal cancer in comparison to non-drinkers. Smoking and drinking together lead to an 8.5 times greater risk of developing oesophageal cancer (48). Most of the studies on oesophageal cancer in South Africa 

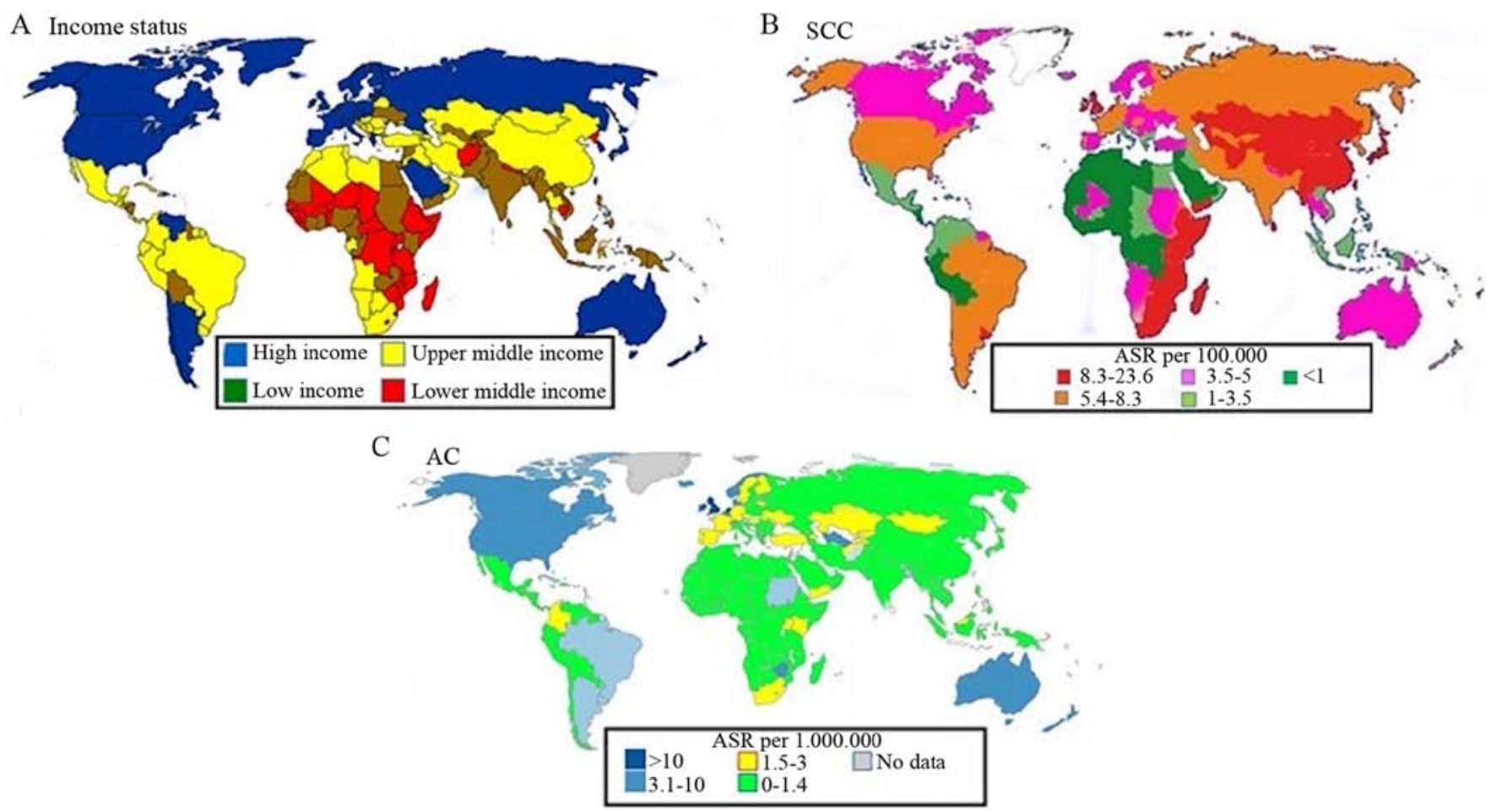

Figure 2. Oesophageal cancer incidence and income status of countries. (A) Countries divided into high, high middle, low middle and low income based on their GDP (145). (B) ASR per 100,000 for SCC. (C) Age-standardised incidence rate (ASR) per 100,000 for Adenocarcinoma (AC) (37,146). SCC, Squamous cell carcinoma; ASR, Age-standardised incidence rate.

have been performed in large urban areas like Johannesburg and Cape Town. Investigations performed amongst rural populations in South Africa, is more challenging hence, such data from is limited in South African databases.

Other risk factors include exposure to environmental smoke (cooking fires) (49), HPV infection (43) and diet. Helicobacteraceae infection may be related to OC risk as it was discovered in roughly $50 \%$ of South African patients with oesophageal carcinoma (50). Dietary risk factors include the use of wild herbs such as Solanum nigrum, the brewing and consumption of traditional maize based beer brewed with maize that may contain fungal mycotoxins or nitrosamines (37), and most importantly the shift to a Western diet. This diet is defined by an increase in the consumption of fats and animal protein (37). High-risk individuals in both the Transkei and KwaZulu-Natal province, are typically poorer with inadequate diets, and consume some class of alcohol and tobacco (51-53). In the Eastern Cape and Transkie, high risk of oesophageal cancer is associated with a diet low in green leafy vegetables and fruit (54). and is associated with low plasma concentrations of vitamins A, E, B12, folic acid and selenium (55). The increased consumption of maize compared to a more traditional diet which is based on other grains such as sorghum, may present additional risks. The maize-rich diet leads to increased levels of prostaglandin $\mathrm{E}_{2}$ (PGE2) in gastric fluid, an enzyme which increases Wnt signaling and proliferation (56).

Tanzania. Like all countries in the Eastern and Southern Africa cancer corridor, Tanzania has a high incidence of esophageal cancer. The age-standardized rate of EC incidence in Tanzania is 9.2 per 10,0000 (57). Generally esophageal carcinoma affects people at a young age in Tanzania, approximately 40 years and older. This is twenty years younger than the average seen in most developed countries (58). The region of Tanzania with the highest number of EC patients is the Kilimanjaro region, with the eastern and central parts of the country having a higher incidence rate of EC compared to the western parts (57). The control of esophageal cancer in Tanzania is hampered by the lack of educational and screening programs as well as a lack of facilities capable of diagnosing and treating the disease (58). There is only one specialized cancer treatment facility in Tanzania, the Ocean Road Cancer Institute (ORCI), located in Dar es Salaam (57). A study of patient numbers being diagnosed at ORCi compared with those receiving treatment showed that over $20 \%$ of EC patients did not receive treatment due to a lack of resources (57). As in other countries, the consumption of hot beverages has been linked to esophageal cancer in Tanzania. In this, case the consumption of hot milky tea (59). Oesophageal cancer in Kenya, especially in the regions bordering Tanzania, is a major health problem. In Kenya oesophageal cancer is more prevalent amongst people living in low socio-economic conditions, and is affected by the level of education and general living conditions (60).

India. OC is also a major health problem in India; particularly in snow-capped Kashmir valley and North-eastern states and is associated with peculiar food and drinking habits such as the drinking of hot salted tea which contains carcinogenic compounds like nitrosamines $(29,61,62)$. Besides salted tea, tobacco smoking (Hukkah or water-pipe), sun dried vegetables are also very common in Kashmir valley and has been shown to be a potential risk factors for increased incidence of OC. In 
addition, high risk HPV type infection has also been reported form areas of OC cases in India $(63,64)$.

China. China is also included in the oesophageal c cancer corridor. China accounts for more than half of all new cases of oesophageal cancer and is the fourth most frequently diagnosed cancer (65). The highest incidence is found in the rural areas (66). Certain areas of China, in Central North China, have the highest oesophageal cancer incidence rate in the world (over 100 per 100 000) (67,68). In China, oesophageal cancer occurs 20-30 times more than in the United States (69). SCC is the major type of oesophageal cancer and more than half of the global SCC cases occur in China (13). Oesophageal cancer is the fourth leading cause of cancer related death in China (65). The Chinese, government is still trying to improve the quality of the cancer registration data in rural areas (13). Like developed countries, an increase in the number of $\mathrm{AC}$ cases and a decrease in the number of SSC cases has been observed in China. The rise in the incidence of AC in China was reported in both urban and rural areas (70).

Apart from alcohol consumption and tobacco use is a high risk factors for oesophageal cancer in China include nutritional factors such as the consumption of fatty meat, salted and pickled vegetables and mouldy food as well as nutritional deficiencies. The populations from many of the areas in China with high oesophageal cancer rates were found to have a diet lacking in selenium, zinc, folate, riboflavin, and vitamins A, $\mathrm{C}, \mathrm{E}$, and B12 (71). These areas also contained high levels of nitrates and nitrosamines in local sources of drinking water and samples of food from local suppliers (72). A relationship also exists between the consumption of hot green tea and the risk of developing oesophageal cancer (73). Lifestyle factors include passive smoking, oesophageal lesions, and infection with Helicobacter pylori, low socioeconomic status and poor oral hygiene. However, a family history of cancer is also an important risk factor associated with increased risk of ESCC (52) and this points to a genetic component. Gastric atrophy, the replacement of dying of gastric cells with intestinal tissues, was also found to be an indication of increased risk for developing oesophageal cancer in Chines populations (74).

Tobacco use amongst Chinese males is currently estimated to be approximately $49.2-56.1 \%$ while it is estimated that only between 2.2-2.6\% of Chinese females smokes (75). Alcohol is a Group 1 carcinogen and the body relies on alcohol dehydrogenases (ADHs) to convert alcohol into acetaldehyde, which is then converted to acetic acid by aldehyde dehydrogenase-2 (ALDH2). Mutations and polymorphisms in either of the genes encoding these two enzymes may decrease the ability to detoxify ethanol leading to cells being exposed to high levels of carcinogens (76). These mutations and polymorphisms are frequently found in individuals that originate from East Asia. ALDH2 mutations lead to the development of a rash or flush response when they consume alcohol. These individuals are at an increased risk of developing oesophageal cancer. A study performed in China, in the Shanxi Province, gave one of the strongest indications that genetics and familial history play a role in oesophageal cancer. This study showed that families with a history of oesophageal cancer were more likely to report a new case within ten years of the first case (77).
Table III. The incidence rates of oesophageal cancer by World area and sex (Torre, $2016 \# 264)$.

\begin{tabular}{lcc}
\hline Country & $\begin{array}{c}\text { Male (ASR of } \\
100,000)\end{array}$ & $\begin{array}{c}\text { Female (ASR } \\
\text { of 100,000) }\end{array}$ \\
\hline Eastern Asia & 16.9 & 5.4 \\
Southern Africa & 17.7 & 6.7 \\
Eastern Africa & 11.9 & 7.8 \\
Northern Europe & 8.1 & 2.7 \\
South America & 7.0 & 2.0 \\
Western Europe & 6.8 & 1.6 \\
South-Central Asia & 6.5 & 3.9 \\
Central and Eastern Europe & 5.6 & 0.8 \\
Northern America & 5.4 & 1.1 \\
Australia/New-Zealand & 5.4 & 1.7 \\
Caribbean & 4.6 & 1.2 \\
Middle Africa & 4.2 & 2.0 \\
Melanesia & 3.6 & 1.4 \\
South-Eastern Asia & 3.6 & 1.0 \\
Southern Europe & 3.2 & 0.6 \\
Western Asia & 2.9 & 2.1 \\
Northern Africa & 2.4 & 1.5 \\
Central America & 1.7 & 0.6 \\
Western Africa & 0.8 & 0.4 \\
\hline
\end{tabular}

AGR, age standardized rate.

Developing countries outside of the OC cancer corridor Brazil. Brazil is a good example of a country with social and healthcare inequalities across geographic regions. Parts of Brazil have the highest incidence of oesophageal cancer in the Western hemisphere. As in other countries alcohol and tobacco consumption are the main factors contributing to this high incidence rate. In the South of Brazil the consumption of hot mate (78). The incidence of oesophageal cancer in Brazil ranges from one to 18 per 100,000 inhabitants and is higher in the southern part of Brazil where it ranges from nine to 18 per 100000 (79). The incidence of oesophageal cancer is intermediate in the central western and North Eastern regions where it ranges from 4 to 9 per 100,000 and is low in the Northern region, where it ranges from 1 to 2 per 100,000 (80). In Brazil cases are mainly diagnosed in individuals over the age of 30 , which is similar to what is seen in Asian countries (81).

Western countries: The United States. The pattern of oesophageal cancer is rapidly changing worldwide. In Western countries, adenocarcinoma of the lower oesophagus has overtaken the previously more prevalent squamous cell carcinoma (82). Adenocarcinoma is the predominant type in Western countries (82). In the US, adenocarcinoma of the oesophagus is reported to be the most common malignancy with the fastest growing incidence, having increased six times in three decades $(82,83)$. This contrasts with studies from the US in which adenocarcinoma accounted for $81 \%$ and squamous cell carcinoma for $17 \%$ (84). In another study among Asian/Pacific Islanders in the US, the rate of oesophageal 
squamous cell carcinoma was $81 \%$ higher than in white populations (85).

The characteristics of oesophageal cancer differ between Asian and western populations (Table III). These differences have been reported to play an important role in the disease (86). In future, studies and clinical practices must consider these ethnic and histological differences and molecular epidemiologic studies may will be helpful in investigating high-risk populations.

\section{Molecular epidemiology of oesophageal cancer}

The risk of OC may be increased by environmental and behavioural factors, of which only a few cases exposed to risk factors develop oesophageal cancer. This indicates that there is a role played by genetics, which may increase the susceptibility of an individual to developing oesophageal disease. The role played by genetic factors has been demonstrated by immigrant epidemiology studies that both genetics and environmental factors are important components that affects oesophageal cancer risk $(87,88)$. TP53 point mutations are common in both adenocarcinoma and ESCC, occurring in approximately $50 \%$ of cases. The mutations in $\mathrm{p} 53$ are detectable in the early stages of cancer development, being detectable in early metaplastic precancerous lesions (89).

The molecular profiles of both adenocarcinoma and SCC have been used to classify theses cancers into further subtypes. ESCC can be divided into three classes. The first class is characterised by genomic alterations in the NRF2 pathway, the second class is characterised by mutations in NOTCH1, ZNF750, KDM6A, KDM2D, PTEN and PIK3R1. Finally the third class is characterized by Phosphoinositide 3-kinase (PI3K) pathway disruption (90). Many of the genetic alterations identified in oesophageal squamous cell cancers are associated with cell cycle progression, apoptosis, DNA repair mechanisms and growth factor receptors. Epidermal growth factor receptor (EGFR) is overexpressed in $50 \%$ of ESCCs, mutations in p53 is found in $92 \%$ of ESCCs, while mutations in NOTCH1 and NOTCH3 are found in 25-33\% of ESCCs. Another pathway that is commonly mutated is the Wnt pathway (91). The mutational profile of ESCC more closely resembles other squamous cell carcinomas than it does other adenocarcinoma[, with complex deletions and translocations being the dominant genetic variations (89). Mutations were also identified in the PI3KCA gene and showed overexpression of the mTOR protein (89).

Adenocarcinoma can also be classified using its molecular characteristics. The first subgroup has many $\mathrm{C}>\mathrm{A} / \mathrm{T}$ mutations. A second group us characterised by defective homologous recombination/chromosome segregation. A final group has a high number of $\mathrm{T}>\mathrm{G}$ mutations mutation with high mutation burden (90). In addition to p53, adenocarcinomas also have a mutated in the tumor suppressor gene p16/CDKN2A. In adenocarcinoma additional genes that are regularly mutated include mediators of the Rho family ELMO1 and DOCK2 (mutated in $17 \%$ of cases). Mutation of these genes lead to an enhancement of cellular motility and an increase in invasion TP53 point mutations are common in both adenocarcinoma and ESCC, occurring in approximately $50 \%$ of cases. The mutations in p53 are detectable in the early stages of cancer development, being detectable in early metaplastic precancerous lesions (89). Other mutated genes are the chromatin-remodeling genes, ARID1A, SMARCA4 and ARID2. Adenocarcinoma is dominated by copy number alterations with frequent large-scale rearrangements, with a larger number of genes being rearranged, amplified or deleted than were affected by point mutations or insertions/deletions (92).

Many genes mutated in adenocarcinoma were also mutated in Barrett's oesophagus. However, p53 mutations are not common in Barrett's oesophagus (39\%) (89). Genes involved in the development of Barrett's oesophagus included genes playing a role in oesophageal development FOXF1[18], FOXSP1 and transcription factors such as CREB, b BARX1 (93). Those that progress from Barret's oesophagus to adenocarcinoma, showing signs of chromosome instability with gene losses and gains. Non-progressors show signs of small localised deletions (89). The molecular epidemiology of ESCC is similar in different population groups, with a population of sub-Saharan ESCC patients showing similar genetic aberrations as those reported in Asian and North American cohorts $(55,94)$. Chinese populations showed a ESCC mutation signature that seems to be linked to mutations in alcohol-metabolizing enzymes. This may help to explain the contribution made by alcohol consumption to ESCC (95).

Genetic risk factors such as single nucleotide polymorphisms (SNPs) are the most common genetic modification that affects the risk of an individual to develop cancer (96). SNPs may influence the risks, outcome and responses to treatment of oesophageal cancer (29). Therefore, it is important to identify genetic markers of oesophageal cancer as they could be used to develop personalised medicine. These markers can also be used as diagnostic biomarkers that can be screened to detect OC at the early stages (97).

Genetic factors. Literature on SC particularly SCC identified candidate genes that are involved in alcohol metabolism, detoxification of carcinogens, DNA repair, apoptosis and cell proliferation $(98,99)$, but their results are not consistent across different populations. This lack in consistency indicates the role played by environmental differences between populations, differences in the level of exposure to different carcinogens as well as differences in sample sizes (98). Genome wide association studies (GWAS) successfully founded hundreds of genetic polymorphisms that are associated with complex diseases including cancer (96). SCC GWAS were conducted in four Asian populations, three in Chinese population and one in a Japanese population (100-103). Two SCC associated single nucleotide polymorphisms (SNPs) were identified in the Japanese study. These were SNPs in alcohol dehydrogenase 1B (rs1229984) and aldehyde dehydrogenase 2 (rs671) gene. These genes encode for metabolic enzymes that are involved in the metabolism of alcohol. Un-metabolised or partially metabolised alcohol is a carcinogen associated with altered SCC risk. The study also indicated gene environmental interactions of rs1229984 and rs671 with alcohol drinking and in the case of rs671, with smoking (101). Two of the Chinese genome association studies reported two susceptibility loci rs2274223 in phospholipase C and rs13042395 in chromosome 20 (104). In a larger GWAS of 2043 cases and 2063 controls in Chinese Han individuals, three new SNPs associated with SCC were identified. These were, rs10052657 in phosphodiesterase 4D, 
rs2014300 in runt related transcription factor 1and rs10484761 close to unc5 homolog C (100). No SNP has been identified that plays a larger role than environmental factors. SNPs have been identified in different population groups in South Africa that are associated with increased risk for developing oesophageal cancer. These studies targeted black Africans and mixed ancestry populations of South Africa and investigated the occurrence of 12 SNPs and one insertion/deletion variant from 8 genes, known to be associated with oesophageal cancer. These studies have indicated that several genetic variants in alcohol metabolism and DNA repair genes are known to contribute to genetic susceptibility to SCC in mixed ancestry populations but not in black South African populations of South Africa or Brazil. This shows that the differences in genetic variants may be explained by genetic history and different environmental exposures (97). This indicates that in low and middle countries more investigations are required that will involve more black populations than white and mixed ancestries populations, since caucasians and those of a mixed ancestry share some genetic history. Mixed population composition differs in genetic, epidemiological and socio demographical characteristics and these may result in association variation between smoking and different types of cancer (105). These differences in different populations are demonstrated in Table III, which shows different incidence rates of OC in different countries with different genetic history and environmental factors.

\section{Diagnosis and prognosis of oesophageal cancer}

Mortality in cancer patients ranged from 15 to $20 \%$ despite many advances in diagnosis and treatment (35). OC prognosis depends on local invasion and spread to regional and distant structures of the body. This type of cancer spread along the body using a variety of pathways such as direct extension, through the lymphatic system and haematogenous metastasis. The lack of an oesophageal wall allows the primary tumour to migrate rapidly into the adjacent structures of the neck and thorax such as the thyroid gland, trachea, larynx, lung, pericardium, aorta and diaphragm (106). The lymphatic drainage of the oesophagus drained by two individual lymphatic plexuses. One lymphatic plexuses develop within the mucosal layer and a second plexus develops within muscular layer. The lymphatic fluid of the oesophagus is able to flow to and communicate with any other part of the oesophagus and migrate in any direction and spread to the intra-thorax or intra-abdominal lymph nodes (107). In order for OC to spread to the liver, lungs, adrenalin glands, bones, kidney and brain, it must spread hematogenously $(9,108)$. The lack of early symptoms complicates diagnosis, while the lack of a hereditary form of the disease makes population based screening impossible unless the screening takes place in high risk areas $(35,109)$. Barrett's oesophagus can develop into cancer. This is because Barrett's oesophagus displays both low and high-grade dysplasia. Patients displaying high-grade dysplasia progress to cancer in approximately $1 \%$ of cases, while those displaying low-grade dysplasia progress to cancer in approximately 0.5 percent of patients. The best way to monitor these patients is through the use of endoscopy (109). However, the use of this screening method has been questioned since high numbers of individuals with reflux symptoms do not develop OC and $40 \%$ of these patients do not have reflux symptoms.
This led to the endoscopic screening to be done in two steps, the detection of an abnormal area through changes in relief, color or in the course of superficial capillaries. This is then followed by morphological characterisation of the lesion $(13,110)$.

In China, several screening methods have been performed and tested in the high-risk areas. These methods includes balloon cytology with smears (111-114), liquid-based balloon cytology $(115)$, occult blood detection $(116,117)$ and endoscopic examination with Lugol's iodine staining and biopsy $(111,118)$. As a result of these studies, endoscopic examinations with iodine staining indicated a sensitive and specificity for the diagnosis of SCC $(119,120)$. None of these studies indicated that any diagnostic method was associated with a reduction in OC incidence or mortality (121).

OC has a poor prognosis. The prognosis of cancer is performed through platelet count, as these are the integral component of the inflammation processes. However, platelet counts are known to be inversely related to cancer prognosis, higher platelet count correlates to a poorer prognosis. The cut off for platelet count as a prognosis factor has been contested. Tumour length is utilized as a prognostic factor in SCC but the length cut off in predicting survival has been debated (122). OC is normally only diagnosed at late stages of tumour development, resulting in higher mortality.

Oesophageal cancer prevention. The prevention of OC differs depending on cell type. The best way to prevent oesophageal cancer is to avoid exposure to environmental risks. In the case of SCC, it is important to reduce or quit tobacco usage and alcohol consumption. Reports indicated that no particular risk factor is responsible for the rise of OC incidence and several strategies are under investigations using agents such as nonsteroidal anti-inflammatory drugs, selenium, alpha-di-fluoro-methyl-ornithine, and retinoids (123). Vegetable and fruit intake are reported to be important preventive strategies, in the case of obesity, which is reported as a risk factor for AC). Follow up of patients with precancerous lesions is recommended. Surveillance, endoscopic screening and surgical resection are important approaches that are suggested to prevent the progression of high-grade dysplasia patients (9). Monitoring the weight of obese patients is also an important strategy of prevention. In Asian and African countries such as China and South Africa, there are preventive approaches of cancer related diseases and $\mathrm{OC}$ is one of them, which are under investigation such as using medicinal plant extracts to induce apoptosis. Both China and African countries have a history of using traditional herbs to treat diseases. These plants are currently being assessed scientifically for their medicinal value. This involves the extraction and purification of crude plant extracts. The purified compounds can then be tested for their ability to treat diseases. For instance, the effectiveness of these compounds in cancer treatment can be assessed by exposing cancer cells to these compounds. This is one of the important strategies required to treat $\mathrm{OC}$ in low and middle countries such as China, India, Brazil and South Africa. These compounds may serve as lead targets for the development of new drugs for the treatment of SCC or even AC in developed countries. Table III, indicates that low and middle-income countries are having high incidence of OC (124). 
Stage 1

Cancer has penetrated into deeper layers of the esophagus wall not reached the lymph nodes esophagus lining.
Stage III

Cancer has grown through the wall of the oesophagus, into nearby organs or tissues. Cancer has spread to nearby lymph nodes.

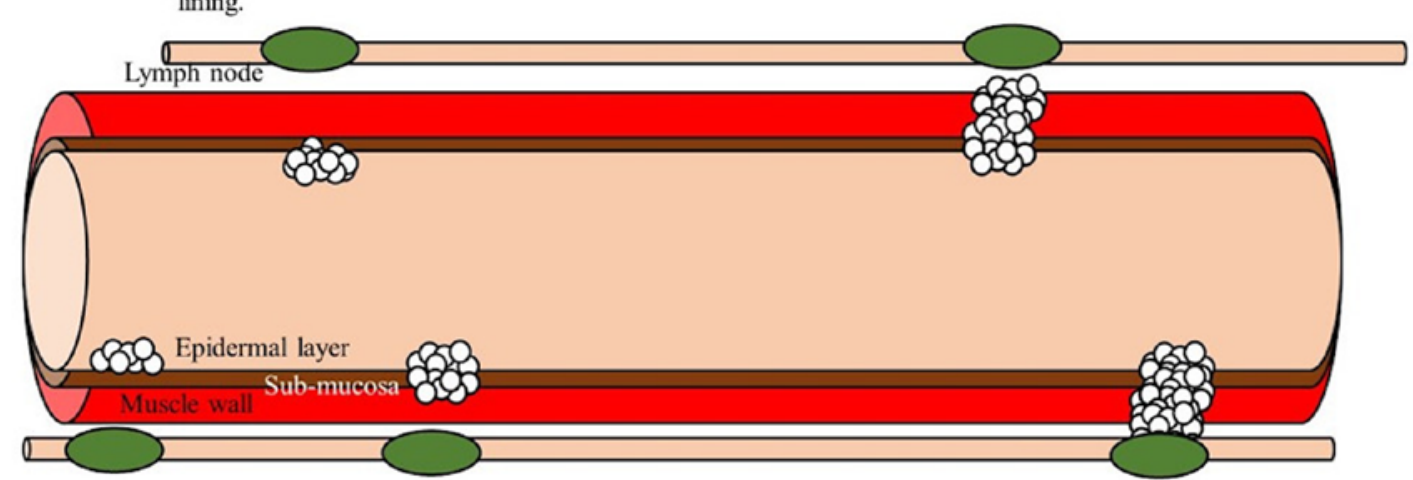

Stage 0

Not true cancer. Abnormal pre-cancer cells
Stage II

Cancer has grown into the main muscle

layer of the esophagus. May have

spread to 1 or 2 nearby lymph nodes.
Stage IV

Cancer has spread to distant

lymph nodes or to other distant organs.

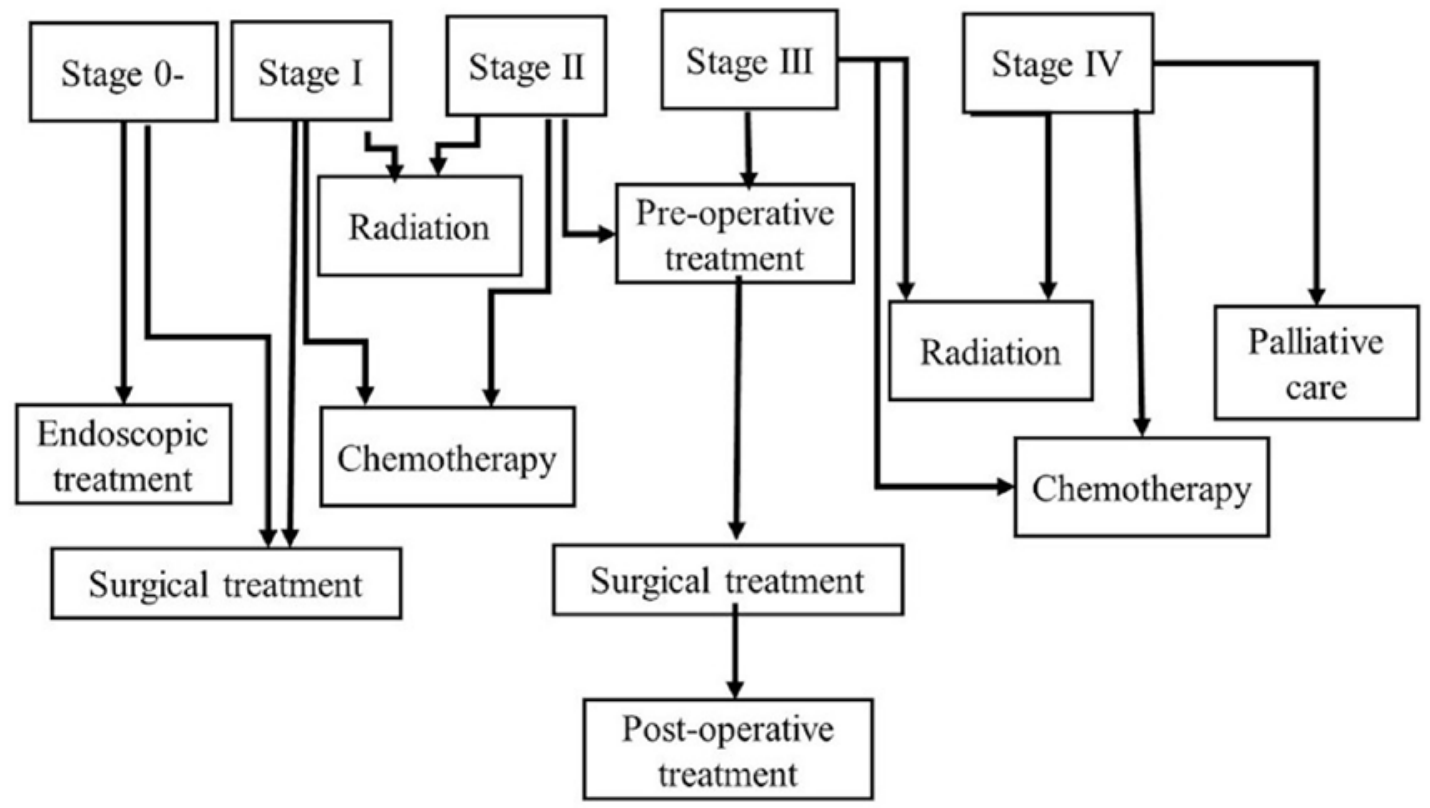

Figure 3. Treatment of oesophageal cancer at different stages (130).

\section{Oesophageal cancer treatment}

The choice of treatment strategy depends on the stage of the cancer (Fig. 3) (125). There are two broad approaches to treat OC, surgical or non-surgical. The appropriate use of surgical approach is determined by the resect ability of the cancer. OC tumours that are locally advanced are good candidates for surgical intervention. Non-surgical approaches are meant for patients with tumours that cannot be surgically removed due to them spreading to various locations in the body or being in-operable due to location $(35,126-128)$.

Surgical treatment. Surgical treatment is divided into six types, endoscopic procedures, resection, lymph-node dissection, and minimally invasive oesophagectomy, neoadjuvant chemotherapy with surgical resection, neoadjuvant chemoradiotherapy surgery, and surgery with adjuvant chemotherapy, radiation or chemoradiation (128). OC may require surgical resection, which includes traditional oesophagostomy and transthoracic approaches $(127,128)$. This surgical option depends on the location of the tumour and the preference of the surgeon (35). Lymph-node dissection surgery is required for patients with oesophageal carcinoma that may be prone to spreading. An oesophagostomy targets the abdominal lymph nodes and the thoracic lymph nodes. This type of dissection is commonly performed in Japan, where incidence of SCC is high (129). It has been noticed that a mortality rate of $1-23 \%$ is associated with oesophagostomy. In order, to reduce the morbidity and mortality associated with oesophagostomy, minimally invasive oesophagostomy was introduced (130).

Immunotherapy. Avoiding the immune system is one of the hallmarks of cancer. Inducing or sustaining the immune 
system to act against cancer cells, is a promising therapeutic strategy. This has led to the development of immunotherapies to treat oesophageal cancer. Different classes of compounds have shown promising results. These include cancer vaccines and immune checkpoint inhibitors (ICI) (131). The development of cancer vaccines is based on the identification of immunogenic cancer antigens (ICA) Cancer vaccines work by initiating antigen specific cytotoxiv $\mathrm{T}$ lymphocyte killing of cancer cells. One approach is to use dendritic cells loaded with multiple Tumor specific antigens, leading to the activation of multiple population of T cells (131). Novel ICAs for ESCC have been identified which match the criteria for being good UCAs as they hive high expression levels in ESCC. They are also essential molecules for the survival of the cancer cells/Despite this, no cancer vaccine has been approved for the treatment of ESCC yet.

As mentioned previously, another type of immunotherapy is the use of immune checkpoint inhibitors. The response of $\mathrm{T}$ cells to cancer cells is regulated by immune checkpoints. This checkpoints are regulated through the binding of inhibitory or stimulatory molecules to receptors, examples of which include Cytotoxic T-lymphocyte-associated antigen 4 (CTLA-4) and programmed cell death protein 1 (PD-1) (131). Both of these checkpoint receptors are expressed on $\mathrm{T}$ cells and act to inhibit $\mathrm{T}$ cells by inhibiting the activity of receptors such as CD28, which activate T cells (131) An ICI named ipilimumab is an anti-CTLA-4 mAb, that is able to treat metastatic melanoma. PD-1 binds to the death-ligand receptor 1 (PD-L1) on cancer cells to induce apoptosis in T cells. PD-L1 is, therefore, an inhibitory B7 family member and is up-regulated in ESCC. Four anti-PD1 mAbs, nivolumab, avelumab, pembrolizumab and atezolizumab are used to treat cancer. Anti-CTLA-4 mAb (ipilimumab) and anti-PD-1 mAb (nivolumab), have both demonstrated the ability to decrease in tumor size $(131,132)$.

Combination therapies. It was suggested that the spread of OC could be controlled by the combination of both chemotherapy and surgery (133). This type of surgery has encountered some problems since patients with SCC or adenocarcinoma shown conflicting results. However, a UK Medical Research Council Oesophageal cancer Working Group study tested the effectiveness of surgery combined with chemotherapy. This study identified a significant improvement in 3-year survival compared with surgery alone (134).

Neoadjuvant chemoradiotherapy and surgery is commonly used in the USA for locally advanced oesophageal cancer. Most randomised studies of this surgery have shown non-significant results. Two studies performed indicated significant survival benefit of this commination treatment $(135,136)$. It has been predicted that adjuvant chemotherapy treated with primary resection might be beneficial especial in patients with node-positive disease $(133,137-139)$. In several randomised trials performed by the Japanese Clinical Oncology Group compared surgery with or without chemotherapy in SCC patients $(137,138)$. In one study, 5-year disease-free survival indicated that combined therapy was favoured (137).

Non-surgical treatment. Non-surgical treatment are divided into six treatment approaches, namely: Radiotherapy; concurrent definitive chemoradiation; salvage oesophagectomy after definitive chemoradiation; advanced metastatic or recurrent disease; biological and targeted therapies; and endoscopic treatment. It is well known that external beam radiotherapy played an important role in the management of un-resectable oesophageal carcinoma. Sustained remission and long-term survival are rarely achieved, although radiotherapy is used in palliative treatment for dysphagia. The preferred approach is chemo-radiotherapy for patients suitable for combined therapy as it provides better palliation than radiotherapy alone and improves the likelihood of long-term progression-free survival (140). Radiotherapy against chemo-radiotherapy was assessed with cisplatin and fluorouracil in patients with $90 \%$ SCC. Chemo-radiotherapy group had an estimated 5-year survival of $27 \%$ and there was no 5-year survival observed in those patients who received radiotherapy alone. It was suggested that although chemo-radiotherapy without surgery is accepted as a SCC treatment, local control is improved when performed with surgery (141).

Salvage oesophagostomy has a higher morbidity and mortality than regular oesophagostomy performed in neoadjuvant methods. A 5-year survival estimation of $25 \%$ in selected patients has shown an increase in perioperative risks. So Salvage oesophagostomy was suggested to be considered for selected patients. It is only an option for patients that respond to chemo-radiotherapy. In most cases by the time of diagnosis of oesophageal carcinoma. The tumour has already started to spread and metasasise (142). Combined short-acting and long-acting narcotics and local radiotherapy are used to treat pain. The effectiveness of chemotherapy or chemo-radiation is observed in approximately $50 \%$ of patients; however, management of pain is effective in almost all patients. Cisplatin and fluoroucil combination play a vital role as supportive care in SCC patients (143). Agents consisting of small molecules and antibodies were created and incorporated into multimodal therapies for tumours (144). The commonly used agents include the angiogenesis inhibitor bevacizumab and the inhibitors of epidermal growth factor receptor; panitumumab; cetuximab; and erlotinib (23).

Endoscopic therapies are used to treat advanced or inoperative cancers and have been suggested as curative approaches for early-stage oesophageal carcinomas. Barrett's oesophagus and early stage cancer might be treatable endoscopically with resection or ablation. Nonsurgical treatment seem to be less reliable than surgical treatment. These treatment options are also more common in well-developed countries. In low and middle countries due to lack of funds and experienced personnel (23).

\section{Conclusions}

The epidemiological differences in the incidence rates of oesophageal cancer, in terms of differences between sexes and economic status of countries, means that very different strategies for diagnosis, treatment and prevention need to be adopted in different areas and for different population groups. Developed countries, with higher rates of $\mathrm{AC}$, have more treatment options due to available resources. Developing countries, with the higher rates of SCC, still rely on surgery. These countries also show far higher incidence of oesophageal cancer, due to high levels of tobacco and alcohol use, poorer nutrition and exposure to other environmental hazards 
such as cooking fires and nitrosamine contamination of foods Environmental factors or race have a vital functional role in oesophageal cancer due to genetic factors, for example where causative genes in black Africans differ from other races. Diagnosis of the disease is challenging since the disease cannot be detected at early stages or early ages. People need to be taught how to prevent this disease and how are these preventions going to help them so that the incidence decrease in these countries. Treatment for oesophageal cancer does not seem reliable; more research is required to improve the diagnosis, risk factors and treatment in this disease.

\section{Acknowledgements}

Not applicable.

\section{Funding}

The authors would like to thank the Medical Research Council of South Africa for funding this research.

\section{Availability of data and materials}

Not applicable.

\section{Authors' contributions}

ZD was responsible for the acquisition of funding and writing of the manuscript. RH, MM, RM and ZMK were responsible for the collection of data. RH, MM, TM, RM and ZMK were responsible for writing the manuscript. RH, TM, RM, ZMK, $\mathrm{CH}, \mathrm{SMW}, \mathrm{RMR}, \mathrm{SH}, \mathrm{GK}$ and DOB were responsible for editing/revising the manuscript. ZD was also responsible for supervising the research group.

\section{Ethics approval and consent to participate}

Not applicable.

\section{Patient consent for publication}

Not applicable.

\section{Competing interests}

Authors declare that they have no competing interests.

\section{References}

1. Henry MA, Lerco MM, Ribeiro PW and Rodrigues MA Epidemiological features of esophageal cancer. Squamous cell carcinoma versus adenocarcinoma. Acta Cir Bras 29: 389-393, 2014.

2. Cook MB, Chow WH and Devesa SS: Oesophageal cancer incidence in the United States by race, sex, and histologic type, 1977-2005. Br J Cancer 101: 855-859, 2009.

3. Bosetti C, Levi F, Ferlay J, Garavello W, Lucchini F, Bertuccio P, Negri E and La Vecchia C: Trends in oesophageal cancer incidence and mortality in Europe. Int J Cancer 122: 1118-1129, 2008.

4. Torre LA, Siegel RL, Ward EM and Jemal A: Global cancer incidence and mortality rates and trends-an update. Cancer Epidemiol Biomarkers Prev 25: 16-27, 2016.
5. Das M, Saikia BJ, Sharma SK, Sekhon GS, Mahanta J and Phukan RK: p16 hypermethylation: A biomarker for increased esophageal cancer susceptibility in high incidence region of North East India. Tumour Biol 36: 1627-1642, 2015.

6. Hongo M, Nagasaki Y and Shoji T: Epidemiology of esophageal cancer: Orient to Occident. Effects of chronology, geography and ethnicity. J Gastroenterol Hepatol 24: 729-735, 2009.

7. Launay L, Dejardin O, Pornet C, Morlais F, Guittet L, Launoy G and Bouvier V: Influence of socioeconomic environment on survival in patients diagnosed with esophageal cancer: A population-based study. Dis Esophagus 25: 723-730, 2012.

8. Lambert R and Hainaut P: Esophageal cancer: Cases and causes (part I). Endoscopy 39: 550-555, 2007.

9. Napier KJ, Scheerer M and Misra S: Esophageal cancer: A review of epidemiology, pathogenesis, staging workup and treatment modalities. World J Gastrointest Oncol 6: 112-120, 2014.

10. Herszényi L and Tulassay Z: Epidemiology of gastrointestinal and liver tumors. Eur Rev Med Pharmacol Sci 14: 249-258, 2010.

11. Zhang L, Ma W and Li Y: Huge primary malignant melanoma of the esophagus: A case report and literature review. Thorac Cancer 4: 479-483, 2013.

12. Gupta V, Coburn N, Kidane B, Hess KR, Compton C, Ringash J, Darling G and Mahar AL: Survival prediction tools for esophageal and gastroesophageal junction cancer: A systematic review. J Thorac Cardiovasc Surg 156: 847-856, 2018.

13. Zhang Y: Epidemiology of esophageal cancer. World J Gastroenterol 19: 5598-5606, 2013.

14. Daly JM, Fry WA, Little AG, Winchester DP, McKee RF, Stewart AK and Fremgen AM: Esophageal cancer: Results of an American College of Surgeons Patient Care Evaluation Study. J Am Coll Surg 190: 562-573, 2000.

15. World Health Organisation: Global status report on alcohol and health, 2014. https://www.who.int/substance_abuse/publications/ global_alcohol_report/en/. Accessed February 15, 2020.

16. World Health Organisation: Prevalence of tobacco smoking, 2015. https://www.who.int/gho/tobacco/use/en/ Accessed November 18, 2018.

17. Akbari MR, Malekzadeh R, Shakeri R, Nasrollahzadeh D, Foumani M, Sun Y, Pourshams A, Sadjadi A, Jafari E, Sotoudeh M, et al: Candidate gene association study of esophageal squamous cell carcinoma in a high-risk region in Iran. Cancer Res 69: 7994-8000, 2009.

18. Stewart BW and Kleihues P (eds): World Cancer Report. IARC Press, Lyon, 2003.

19. Brown LM, Hoover RN, Greenberg RS, Schoenberg JB, Schwartz AG, Swanson GM, Liff JM, Silverman DT, Hayes RB and Pottern LM: Are racial differences in squamous cell esophageal cancer explained by alcohol and tobacco use? J Natl Cancer Inst 86: 1340-1345, 1994.

20. Muwonge R, Ramadas K, Sankila R, Thara S, Thomas G, Vinoda J and Sankaranarayanan R: Role of tobacco smoking, chewing and alcohol drinking in the risk of oral cancer in Trivandrum, India: A nested case-control design using incident cancer cases. Oral Oncol 44: 446-454, 2008.

21. Blot W, McLaughlin J and Fraumeni J Jr (eds): Esophageal cancer. Oxford University Press Oxford, 2006.

22. Blot W and Tarone R: Esophageal cancer. In: Cancer epidemiology and prevention. In: Thun M, Linet M, Cerhan L, Haiman $\mathrm{C}$ and Schottenfeld D (eds.) Oxford University Press, Oxford, pp 579-592, 2006

23. Blot W, McLaughlin J and Fraumeni JJ Jr: Esophageal Cancer. In: Cancer Epidemiology and Prevention. Thun M, Linet M, Cerhan J, Haiman C and Schottenfeld D (eds.) 4th edition. Oxford University Press, Oxford, pp 697-707, 2006.

24. Nieman DR and Peters JH: Treatment strategies for esophageal cancer. Gastroenterol Clin North Am 42: 187-197, 2013.

25. Wang KK and Sampliner RE; Practice Parameters Committee of the American College of Gastroenterology: Updated guidelines 2008 for the diagnosis, surveillance and therapy of Barrett's esophagus. Am J Gastroenterol 103: 788-797, 2008.

26. Khan NA, Teli MA, Mohib-U1 Haq M, Bhat GM, Lone MM and Afroz F: A survey of risk factors in carcinoma esophagus in the valley of Kashmir, Northern India. J Cancer Res Ther 7: $15-18,2011$.

27. Islami F, Kamangar F, Nasrollahzadeh D, Aghcheli K, Sotoudeh M,Abedi-Ardekani B,Merat S,Nasseri-MoghaddamS, Semnani S, Sepehr A, et al: Socio-economic status and oesophageal cancer: Results from a population-based case-control study in a high-risk area. Int J Epidemiol 38: 978-988, 2009. 
28. Siddiqi M, Kumar R, Kaul D, Spiegelhalder B and Preussmann R: Salivary nitrate and nitrite concentrations from a sample population of children and adults in high risk area for esophageal and gastric cancers in Kashmir, India. Cancer Lett 64: 133-136, 1992

29. Gupta B and Kumar N: Worldwide incidence, mortality and time trends for cancer of the oesophagus. Eur J Cancer Prev 26: 107-118, 2017.

30. Hussain S, M Y, Thakur N, Salam I, Singh N, Mir MM, Bhat MA, Siddiqi MA, Das BC and Bharadwaj M: Association of cyclin D1 gene polymorphisms with risk of esophageal squamous cell carcinoma in Kashmir Valley: A high risk area. Mol Carcinog 50 : 487-498, 2011.

31. Enzinger PC and Mayer RJ: Esophageal cancer. N Engl J Med 349: 2241-2252, 2003

32. Arnold M, Soerjomataram I, Ferlay J and Forman D: Global incidence of oesophageal cancer by histological subtype in 2012 Gut 64: 381-387, 2015.

33. Eslick GD: Epidemiology of esophageal cancer. Gastroenterol Clin North Am 38: 17-25, 2009.

34. Thuler FP, Forones NM and Ferrari AP: Advanced esophageal cancer: Still a delayed diagnosis. Arq Gastroenterol 43: 206-211, 2006.

35. Barrios E, Sierra MS, Musetti C and Forman D: The burden of oesophageal cancer in Central and South America. Cancer Epidemiol 44 (Suppl 1): S53-S61, 2016.

36. Pennathur A, Gibson MK, Jobe BA and Luketich JD: Oesophageal carcinoma. Lancet 381: 400-412, 2013.

37. Bray F, Ferlay J, Soerjomataram I, Siegel RL, Torre LA and Jemal A: Global cancer statistics 2018: GLOBOCAN estimates of incidence and mortality worldwide for 36 cancers in 185 countries. CA Cancer J Clin 68: 394-424, 2018.

38. Segal I, Reinach SG and de Beer M: Factors associated with oesophageal cancer in Soweto, South Africa. Br J Cancer 58 681-686, 1988.

39. Higginson $\mathrm{J}$ and Oettle AG: Cancer incidence in the Bantu and 'Cape Colored' races of South Africa: Report of a cancer survey in the Transvaal (1953-55). J Natl Cancer Inst 24: 589-671, 1960

40. Oettl AJSAMJ: An epidemic of oesophageal carcinoma in Africa. 37: 435, 1963.

41. Rose EF: Esophageal cancer in the Transkei: 1955-69. J Natl Cancer Inst 51: 7-16, 1973.

42. Jemal A, Bray F, Forman D, O'Brien M, Ferlay J, Center M and Parkin DM: Cancer burden in Africa and opportunities for prevention. Cancer 118: 4372-4384, 2012.

43. Blot WJ: Esophageal cancer trends and risk factors. Semin Oncol 21: 403-410, 1994.

44. Sammon AM: Carcinogens and endemic squamous cancer of the oesophagus in Transkei, South Africa. Environmental initiation is the dominant factor; tobacco or other carcinogens of low potency or concentration are sufficient for carcinogenesis in the predisposed mucosa. Med Hypotheses 69: 125-131, 2007.

45. Makaula AN, Marasas WF, Venter FS, Badenhorst CJ, Bradshaw D and Swanevelder S: Oesophageal and other cancer patterns in four selected districts of the Transkei, Southern Africa: 1985-1990. Afr J Health Sci 3: 11-15, 1996.

46. Bizos D, Morgan H, Motha N, Makda M, Domingo A, Tiedt S Wing J, Munanga M, Tembo J, Hale M and Bizos D: Comparison of the incidence of oesophageal cancer in two 6-year periods from selected hospitals in and around Gauteng Province, South Africa. South Afr J Surg 53: 55-58, 2015.

47. Lagergren J, Bergström R, Lindgren A and Nyrén O: Symptomatic gastroesophageal reflux as a risk factor for esophageal adenocarcinoma. N Engl J Med 340: 825-831, 1999.

48. Reddy P,Zuma K, Shisana O, Jonas K and Sewpaul R: Prevalence of tobacco use among adults in South Africa: Results from the first South African National Health and Nutrition Examination Survey. S Afr Med J 105: 648-655, 2015.

49. Sewram V, Sitas F, O'Connell D and Myers J: Tobacco and alcohol as risk factors for oesophageal cancer in a high incidence area in South Africa. Cancer Epidemiol 41: 113-121, 2016.

50. Dlamini Z and Bhoola K: Esophageal cancer in African blacks of Kwazulu Natal, South Africa: An epidemiological brief. Ethn Dis 15: 786-789, 2005.

51. Schandl L, Malfertheiner P and Ebert MP: Prevention of gastric cancer by Helicobacter pylori eradication? Dig Dis 20: 18-22, 2002.

52. Lin Y, Totsuka Y, Shan B, Wang C, Wei W, Qiao Y, Kikuchi S, Inoue M, Tanaka H and He Y: Esophageal cancer in high-risk areas of China: Research progress and challenges. Ann Epidemiol 27: 215-221, 2017.
53. Long N, Moore MA, Chen W, Gao CM, Lai MS, Mizoue T, Oyunchimeg D, Park S, Shin HR, Tajima K, et al: Cancer epidemiology and control in north-East Asia-past, present and future. Asian Pac J Cancer Prev 11 (Suppl 2): S107-S148, 2010.

54. Wang AH, Sun CS, Li LS, Huang JY and Chen QS: Relationship of tobacco smoking CYP1A1 GSTM1 gene polymorphism and esophageal cancer in Xi'an. World J Gastroenterol 8: 49-53, 2002.

55. Sewram V, Sitas F, O'Connell D and Myers J: Diet and esophageal cancer risk in the Eastern Cape Province of South Africa. Nutr Cancer 66: 791-799, 2014.

56. Jaskiewicz K: Oesophageal carcinoma: Cytopathology and nutritional aspects in aetiology. Anticancer Res 9: 1847-1852, 1989.

57. Pink RC, Bailey TA, Iputo JE, Sammon AM, Woodman AC and Carter DR: Molecular basis for maize as a risk factor for esophageal cancer in a South African population via a prostaglandin $\mathrm{E}_{2}$ positive feedback mechanism. Nutr Cancer 63: 714-721, 2011.

58. Gabel JV, Chamberlain RM, Ngoma T, Mwaiselage J, Schmid KK, Kahesa C and Soliman AS: Clinical and epidemiologic variations of esophageal cancer in Tanzania. World J Gastrointest Oncol 8: 314-320, 2016.

59. McHembe MD, Rambau PF, Chalya PL, Jaka H, Koy M and Mahalu W: Endoscopic and clinicopathological patterns of esophageal cancer in Tanzania: Experiences from two tertiary health institutions. World J Surg Oncol 11: 257, 2013.

60. Munishi MO, Hanisch R, Mapunda O, Ndyetabura T, Ndaro A, Schüz J, Kibiki G and McCormack V: Africa's oesophageal cancer corridor: Do hot beverages contribute? Cancer Causes Control 26: 1477-1486, 2015.

61. Patel K, Wakhisi J, Mining S, Mwangi A and Patel R: Esophageal cancer, the topmost cancer at MTRH in the Rift Valley, Kenya, and its potential risk factors. ISRN Oncol 2013: 503249, 2013.

62. Khuroo MS, Zargar SA, Mahajan R and Banday MA: High incidence of oesophageal and gastric cancer in Kashmir in a population with special personal and dietary habits. Gut 33: 11-15, 1992.

63. Murphy G, McCormack V, Abedi-Ardekani B, Arnold M, Camargo MC, Dar NA, Dawsey SM, Etemadi A, Fitzgerald RC, Fleischer DE, et al: International cancer seminars: A focus on esophageal squamous cell carcinoma. Ann Oncol 28: 2086-2093, 2017.

64. Katiyar S, Hedau S, Jain N, Kar P, Khuroo MS, Mohanta J, Kumar S, Gopalkrishna V, Kumar N and Das BC: p53 gene mutation and human papillomavirus (HPV) infection in esophageal carcinoma from three different endemic geographic regions of India. Cancer Lett 218: 69-79, 2005.

65. Salam I, Hussain S, Mir MM, Dar NA, Abdullah S, Siddiqi MA, Lone RA, Zargar SA, Sharma S, Hedau S, et al: Aberrant promoter methylation and reduced expression of p16 gene in esophageal squamous cell carcinoma from Kashmir valley: A high-risk area. Mol Cell Biochem 332: 51-58, 2009.

66. Ferlay J, Shin HR, Bray F, Forman D, Mathers C and Parkin DM: Estimates of worldwide burden of cancer in 2008: GLOBOCAN 2008. Int J Cancer 127: 2893-2917, 2010.

67. Chen M, Huang J, Zhu Z, Zhang J and Li K: Systematic review and meta-analysis of tumor biomarkers in predicting prognosis in esophageal cancer. BMC Cancer 13: 539, 2013.

68. Guo W, Blot WJ, Li JY, Taylor PR, Liu BQ, Wang W, Wu YP, Zheng W, Dawsey SM, Li B, et al: A nested case-control study of oesophageal and stomach cancers in the Linxian nutrition intervention trial. Int J Epidemiol 23: 444-450, 1994.

69. Parkin DM, Stjernsward J and Muir CS: Estimates of the worldwide frequency of twelve major cancers. Bull World Health Organ 62: 163-182, 1984.

70. Chen W, Zheng R, Baade PD, Zhang S, Zeng H, Bray F, Jemal A, Yu XQ and He J: Cancer statistics in China, 2015. CA Cancer J Clin 66: 115-132, 2016.

71. Pohl $\mathrm{H}$ and Welch HG: The role of overdiagnosis and reclassification in the marked increase of esophageal adenocarcinoma incidence. J Natl Cancer Inst 97: 142-146, 2005.

72. Taylor PR, Li B, Dawsey SM, Li JY, Yang CS, Guo W and Blot WJ: Prevention of esophageal cancer: The nutrition intervention trials in Linxian, China. Linxian Nutrition Intervention Trials Study Group. Cancer Res 54 (Suppl 7): 2029S-2031S, 1994.

73. Yang CS: Research on esophageal cancer in China: A review. Cancer Res 40: 2633-2644, 1980.

74. Wu M, Liu AM, Kampman E, Zhang ZF, Van't Veer P, Wu DL, Wang PH, Yang J, Qin Y, Mu LN, et al: Green tea drinking, high tea temperature and esophageal cancer in high- and low-risk areas of Jiangsu Province, China: A population-based case-control study. Int J Cancer 124: 1907-1913, 2009. 
75. Kamangar F, Diaw L, Wei WQ, Abnet CC, Wang GQ, Roth MJ, Liu B, Lu N, Giffen C, Qiao YL and Dawsey SM: Serum pepsinogens and risk of esophageal squamous dysplasia. Int J Cancer 124: 456-460, 2009.

76. Li Q, Hsia J and Yang G: Prevalence of smoking in China in 2010. N Engl J Med 364: 2469-2470, 2011.

77. Salaspuro M: Acetaldehyde and gastric cancer. J Dig Dis 12 : $51-59,2011$.

78. Kollarova H, Machova L, Horakova D, Janoutova G and Janout V: Epidemiology of esophageal cancer-an overview article. Biomed Pap Med Fac Univ Palacky Olomouc Czech Repub 151: 17-20, 2007.

79. Ribeiro Pinto LF, Teixeira Rossini AM, Albano RM Felzenszwalb I, de Moura Gallo CV, Nunes RA and Andreollo NA: Mechanisms of esophageal cancer development in Brazilians. Mutat Res 544: 365-373, 2003.

80. Mota OM, Curado MP, Oliveira JC, Martins E and Cardoso DM: Risk factors for esophageal cancer in a low-incidence area of Brazil. Sao Paulo Med J 131: 27-34, 2013

81. Gao Y, He Y, Xu J, Xu L, Du J, Zhu C, Gu H, Ma H, Hu Z, Jin G, et al: Genetic variants at 4q21, 4q23 and 12q24 are associated with esophageal squamous cell carcinoma risk in a Chinese population. Hum Genet 132: 649-656, 2013.

82. Vioque J, Barber X, Bolumar F, Porta M, Santibáñez M, de la Hera MG and Moreno-Osset E; PANESOES Study Group: Esophageal cancer risk by type of alcohol drinking and smoking: a case-control study in Spain. BMC Cancer 8: 221, 2008.

83. Pun C, Aryal G, Basyal R, Shrestha S, Pathak T, Bastola S, Neupane S, Shrestha BM, Thakur BK and Lee MC: Histological pattern of esophageal cancer at BP Koirala memorial cancer hospital in Nepal: A three year retrospective study. J Pathol Nepal 2: 277-281, 2012.

84. Ali A, Ersumo T and Johnson O: Oesophageal carcinoma in Tikur Anbessa Hospital, Addis Ababa. East Afr Med J 75: 590-593, 1998.

85. Schlansky B, Dimarino AJ Jr, Loren D, Infantolino A, Kowalski T and Cohen S: A survey of oesophageal cancer: Pathology, stage and clinical presentation. Aliment Pharmacol Ther 23: 587-593, 2006.

86. Cherian JV, Sivaraman R, Muthusamy AK and Jayanthi V: Carcinoma of the esophagus in Tamil Nadu (South India) 16-year trends from a tertiary center. J Gastrointestin Liver Dis 16: 245-249, 2007

87. Fan YJ, Song X, Li JL, Li XM, Liu B, Wang R, Fan ZM and Wang LD: Esophageal and gastric cardia cancers on 4238 Chinese patients residing in municipal and rural regions: A histopathological comparison during 24-year period. World J Surg 32: 1980-1988, 2008.

88. Gomez SL, Le GM, Clarke CA, Glaser SL, France AM and West DW: Cancer incidence patterns in Koreans in the US and in Kangwha, South Korea. Cancer Causes Control 14: 167-174, 2003.

89. Stellman SD and Wang QS: Cancer mortality in Chinese immigrants to New York City. Comparison with Chinese in Tianjin and with United States-born whites. Cancer 73: 1270-1275, 1994

90. Testa U, Castelli G and Pelosi E: Esophageal Cancer: Genomic and molecular characterization, stem cell compartment and clonal evolution. Medicines (Basel) 4: E67, 2017.

91. Tomczak K, Czerwinska P and Wiznerowicz M: The Cancer Genome Atlas (TCGA): An immeasurable source of knowledge. Contemp Oncol (Pozn) 19: A68-A77, 2015.

92. Agrawal N, Jiao Y, Bettegowda C, Hutfless SM, Wang Y, David S, Cheng Y, Twaddell WS, Latt NL, Shin EJ, et al: Comparative genomic analysis of esophageal adenocarcinoma and squamous cell carcinoma. Cancer Discov 2 899-905, 2012.

93. Secrier M, Li X, de Silva N, Eldridge MD, Contino G, Bornschein J, MacRae S, Grehan N, O'Donovan M, Miremadi A, et al: Mutational signatures in esophagea adenocarcinoma define etiologically distinct subgroups with therapeutic relevance. Nat Genet 48: 1131-1141, 2016.

94.Levine DM, Ek WE, Zhang R, Liu X, Onstad L, Sather C, Lao-Sirieix P, Gammon MD, Corley DA, Shaheen NJ, et al: A genome-wide association study identifies new susceptibility loci for esophageal adenocarcinoma and Barrett's esophagus. Nat Genet 45: 1487-1493, 2013.

95. Sawada G, Niida A, Uchi R, Hirata H, Shimamura T, Suzuki Y, Shiraishi Y, Chiba K, Imoto S, Takahashi Y, et al: Genomic landscape of esophageal squamous cell carcinoma in a Japanese population. Gastroenterology 150: 1171-1182, 2016.
96. Chang J, Tan W, Ling Z, Xi R, Shao M, Chen M, Luo Y, Zhao Y, Liu Y, Huang X, et al: Genomic analysis of oesophageal squamous-cell carcinoma identifies alcohol drinking-related mutation signature and genomic alterations. Nat Commun 8: 15290, 2017.

97. Manolio TA: Genomewide association studies and assessment of the risk of disease. N Engl J Med 363: 166-176, 2010.

98. Zhang J, Bowers J, Liu L, Wei S, Gowda GA, Hammoud Z and Raftery D: Esophageal cancer metabolite biomarkers detected by LC-MS and NMR methods. PLoS One 7: e30181, 2012.

99. Bye H, Prescott NJ, Matejcic M, Rose E, Lewis CM, Parker MI and Mathew CG: Population-specific genetic associations with oesophageal squamous cell carcinoma in South Africa. Carcinogenesis 32: 1855-1861, 2011.

100. Lao-Sirieix P, Caldas C and Fitzgerald RC: Genetic predisposition to gastro-oesophageal cancer. Curr Opin Genet Dev 20: 210-217, 2010

101. Abnet CC, Freedman ND, Hu N, Wang Z, Yu K, Shu XO, Yuan JM, Zheng W, Dawsey SM, Dong LM, et al: A shared susceptibility locus in PLCE1 at 10q23 for gastric adenocarcinoma and esophageal squamous cell carcinoma. Nat Genet 42 : 764-767, 2010.

102. Cui R, Kamatani Y, Takahashi A, Usami M, Hosono N, Kawaguchi T, Tsunoda T, Kamatani N, Kubo M, Nakamura Y and Matsuda K: Functional variants in ADH1B and ALDH2 coupled with alcohol and smoking synergistically enhance esophageal cancer risk. Gastroenterology 137: 1768-1775, 2009.

103. Wang Y, Adachi Y, Imsumran A, Yamamoto H, Piao W, Li H, Ii M, Arimura Y, Park MY, Kim D, et al: Targeting for insulin-like growth factor-I receptor with short hairpin RNA for human digestive/gastrointestinal cancers. J Gastroenterol 45: 159-170, 2010.

104. Wu C, Hu Z, He Z, Jia W, Wang F, Zhou Y, Liu Z, Zhan Q, Liu Y, Yu D, et al: Genome-wide association study identifies three new susceptibility loci for esophageal squamous-cell carcinoma in Chinese populations. Nat Genet 43: 679-684, 2011.

105. Abnet CC, Wang Z, Song X, Hu N, Zhou FY, Freedman ND, Li XM, Yu K, Shu XO, Yuan JM, et al: Genotypic variants at 2q33 and risk of esophageal squamous cell carcinoma in China: A meta-analysis of genome-wide association studies. Hum Mol Genet 21: 2132-2141,2012.

106. Moura MA, Bergmann A, Aguiar SS and Thuler LC: The magnitude of the association between smoking and the risk of developing cancer in Brazil: A multicenter study. BMJ Open 4: e003736, 2014.

107. Postlethwait RW: Carcinoma of the thoracic esophagus. Surg Clin North Am 63: 933-940, 1983.

108. Mandard AM, Chasle J, Marnay J, Villedieu B, Bianco C, Roussel A, Elie H and Vernhes JC: Autopsy findings in 111 cases of esophageal cancer. Cancer 48: 329-335, 1981.

109. Quint LE, Hepburn LM, Francis IR, Whyte RI and Orringer MB: Incidence and distribution of distant metastases from newly diagnosed esophageal carcinoma. Cancer 76: 1120-1125, 1995.

110. Mao WM, Zheng WH and Ling ZQ: Epidemiologic risk factors for esophageal cancer development. Asian Pac J Cancer Prev 12: 2461-2466, 2011.

111. Lambert R: Endoscopy in screening for digestive cancer. World J Gastrointest Endosc 4: 518-525, 2012.

112. Dawsey SM, Wang GQ, Weinstein WM,Lewin KJ,Liu FS, Wiggett S, Nieberg RK, Li JY and Taylor PR: Squamous dysplasia and early esophageal cancer in the Linxian region of China: Distinctive endoscopic lesions. Gastroenterology 105: 1333-1340, 1993.

113. Roth MJ, Liu SF, Dawsey SM, Zhou B, Copeland C, Wang GQ, Solomon D, Baker SG, Giffen CA and Taylor PR: Cytologic detection of esophageal squamous cell carcinoma and precursor lesions using balloon and sponge samplers in asymptomatic adults in Linxian, China. Cancer 80: 2047-2059, 1997.

114. Shen O, Liu SF, Dawsey SM, Cao J, Zhou B, Wang DY, Cao SG, Zhao HZ, Li GY, Taylor PR, et al: Cytologic screening for esophageal cancer: Results from 12,877 subjects from a high-risk population in China. Int J Cancer 54: 185-188, 1993.

115. Shu YJ: Cytopathology of the esophagus. An overview of esophageal cytopathology in China. Acta Cytol 27: 7-16, 1983.

116. Pan QJ, Roth MJ, Guo HQ, Kochman ML, Wang GQ, Henry M, Wei WQ, Giffen CA, Lu N, Abnet CC, et al: Cytologic detection of esophageal squamous cell carcinoma and its precursor lesions using balloon samplers and liquid-based cytology in asymptomatic adults in Llinxian, China. Acta Cytol 52: 14-23, 2008.

117. Qin DX, Wang GQ, Yuan FL, Tang MZ, Li MS and Zhang ZL: Screening for upper digestive tract cancer with an occult blood bead detector. Investigation of a normal north China population. Cancer 62: 1030-1034, 1988 
118. Qin DX, Wang GQ, Zuo JH, Zhang XH, Yuan FL, Li MS, Wu CR and Ju CL: Screening of esophageal and gastric cancer by occult blood bead detector. Cancer 71: 216-218, 1993.

119. Dawsey SM, Lewin KJ, Liu FS, Wang GQ and Shen Q: Esophageal morphology from Linxian, China. Squamous histologic findings in 754 patients. Cancer 73: 2027-2037, 1994.

120. Dawsey SM, Fleischer DE, Wang GQ, Zhou B, Kidwell JA, Lu N, Lewin KJ, Roth MJ, Tio TL and Taylor PR: Mucosal iodine staining improves endoscopic visualization of squamous dysplasia and squamous cell carcinoma of the esophagus in Linxian, China. Cancer 83: 220-231, 1998.

121. Muto M, Minashi K, Yano T, Saito Y, Oda I, Nonaka S, Omori T, Sugiura H, Goda K, Kaise M, et al: Early detection of superficial squamous cell carcinoma in the head and neck region and esophagus by narrow band imaging: A multicenter randomized controlled trial. J Clin Oncol 28: 1566-1572, 2010.

122. Wei WQ, Chen ZF, He YT, Feng H, Hou J, Lin DM, Li XQ, Guo CL, Li SS, Wang GQ, et al: Long-Term Follow-up of a community assignment, One-time endoscopic screening study of esophageal cancer in China. J Clin Oncol 33: 1951-1957, 2015.

123. Feng JF, Huang Y, Lu WS and Chen QX: Preoperative platelet count in esophageal squamous cell carcinoma: Is it a prognostic factor? Langenbeck's Arch Surg 398: 1115-1122, 2013.

124. Almhanna K, Meredith KL, Hoffe SE, Shridhar R and Coppola D: Targeting the human epidermal growth factor receptor 2 in esophageal cancer. Cancer Control 20: 111-116, 2013.

125. Ying J, Zhang M, Qiu X and Lu Y: The potential of herb medicines in the treatment of esophageal cancer. Biomed Pharmacotherapy 103: 381-390, 2018.

126. Krasna MJ: Stage-specific therapy for cancer of the oesophagus: A new 'cancer of the elderly'. Drugs Aging 26: 185-194, 2009.

127. Hagen JA, DeMeester SR, Peters JH, Chandrasoma P and DeMeester TR: Curative resection for esophageal adenocarcinoma: Analysis of 100 en bloc esophagectomies. Ann Surg 234 520-531, 2001

128. Pennathur A and Luketich JD: Resection for esophageal cancer: Strategies for optimal management. Ann Thoracic Surg 85 (Suppl): S751-S756, 2008.

129. Pennathur A, Zhang J, Chen $\mathrm{H}$ and Luketich JD: The 'best operation' for esophageal cancer? Ann Thorac Surg 89 (Suppl): S2163-S2167, 2010.

130. Nishihira T, Hirayama K and Mori S: A prospective randomized trial of extended cervical and superior mediastinal lymphadenectomy for carcinoma of the thoracic esophagus. Am J Surg 175: 47-51, 1998.

131. Birkmeyer JD, Sun Y, Goldfaden A, Birkmeyer NJ and Stukel TA: Volume and process of care in high-risk cancer surgery. Cancer 106: 2476-2481, 2006

132. Mimura K, Yamada L, Ujiie D, Hayase S, Tada T, Hanayama H, Thar Min AK, Shibata M, Momma T, Saze Z, et al: Immunotherapy for esophageal squamous cell carcinoma: A review. Fukushima J Med Sci 64: 46-53, 2018.

133. Vrana D, Matzenauer M, Neoral Č, Aujeský R, Vrba R, Melichar B, Rušarová N, Bartoušková M and Jankowski J: From Tumor immunology to immunotherapy in gastric and esophageal cancer. Int J Mol Sci 20: E13, 2018.

134. Pennathur A, Luketich JD, Landreneau RJ, Ward J, Christie NA, Gibson MK, Schuchert M, Cooper K, Land SR and Belani CP: Long-term results of a phase II trial of neoadjuvant chemotherapy followed by esophagectomy for locally advanced esophageal neoplasm. Ann Thorac Surg 85: 1930-1937, 2008.
135. Cunningham D, Allum WH, Stenning SP, Thompson JN, Van de Velde CJ, Nicolson M, Scarffe JH, Lofts FJ, Falk SJ, Iveson TJ, et al: Perioperative chemotherapy versus surgery alone for resectable gastroesophageal cancer. N Engl J Med 355 11-20, 2006

136. Tepper J, Krasna MJ, Niedzwiecki D, Hollis D, Reed CE, Goldberg R, Kiel K, Willett C, Sugarbaker D and Mayer R: Phase III trial of trimodality therapy with cisplatin, fluorouracil, radiotherapy, and surgery compared with surgery alone for esophageal cancer: CALGB 9781. J Clin Oncol 26: 1086-1092, 2008.

137. Walsh TN, Noonan N, Hollywood D, Kelly A, Keeling N and Hennessy TP: A comparison of multimodal therapy and surgery for esophageal adenocarcinoma. N Engl J Med 335: 462-467, 1996.

138. Ando N, Iizuka T, Ide H, Ishida K, Shinoda M, Nishimaki T, Takiyama W, Watanabe H, Isono K, Aoyama N, et al: Surgery plus chemotherapy compared with surgery alone for localized squamous cell carcinoma of the thoracic esophagus: A Japan Clinical Oncology Group Study-JCOG9204. J Clin Oncol 21: 4592-4596, 2003

139. Ando N, Ozawa S, Kitagawa Y, Takeuchi H and Kitajima M: Salvage surgery for the T4 esophageal cancer following downstaging by neoadjuvant chemoradiotherapy. Nihon Geka Gakkai Zasshi 98: 767-772, 1997 (In Japanese).

140. Armanios M, Xu R, Forastiere AA, Haller DG, Kugler JW and Benson AB III; Eastern Cooperative Oncology Group: Adjuvant chemotherapy for resected adenocarcinoma of the esophagus, gastro-esophageal junction, and cardia: Phase II trial (E8296) of the Eastern Cooperative Oncology Group. J Clin Oncol 22: 4495-4499, 2004.

141. Kleinberg L and Forastiere AA: Chemoradiation in the management of esophageal cancer. J Clin Oncol 25: 4110-4117, 2007.

142. Stahl M, Wilke H, Stuschke M, Walz MK, Fink U, Molls M, Siewert JR, Schroeder M, Makoski HB, Schmidt U, et al: Clinical response to induction chemotherapy predicts local control and long-term survival in multimodal treatment of patients with locally advanced esophageal cancer. J Cancer Res Clin Oncol 131: 67-72, 2005

143. Polednak AP: Trends in survival for both histologic types of esophageal cancer in US surveillance, epidemiology and end results areas. Int J Cancer 105: 98-100, 2003.

144. Homs MY, Steyerberg EW, Eijkenboom WM and Siersema PD: Predictors of outcome of single-dose brachytherapy for the palliation of dysphagia from esophageal cancer. Brachytherapy 5: 41-48, 2006

145. Shah MA, Ramanathan RK, Ilson DH, Levnor A, D'Adamo D, O'Reilly E, Tse A, Trocola R, Schwartz L, Capanu M, et al: Multicenter phase II study of irinotecan, cisplatin, and bevacizumab in patients with metastatic gastric or gastroesophageal junction adenocarcinoma. J Clin Oncol 24: 5201-5206, 2006.

146. Batouli A, Jahanshahi P, Gross CP, Makarov DV and Yu JB: The global cancer divide: Relationships between national healthcare resources and cancer outcomes in high-income vs. middle- and low-income countries. J Epidemiol Glob Health 4: 115-124, 2014.

This work is licensed under a Creative Commons Attribution-NonCommercial-NoDerivatives 4.0 International (CC BY-NC-ND 4.0) License. 